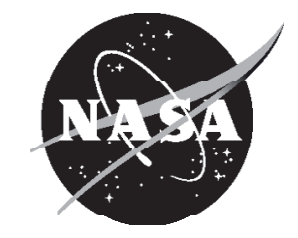

\title{
NEXT Ion Thruster Performance Dispersion Analyses
}

George C. Soulas and Michael J. Patterson

Glenn Research Center, Cleveland, Ohio 


\section{NASA STI Program . . . in Profile}

Since its founding, NASA has been dedicated to the advancement of aeronautics and space science. The NASA Scientific and Technical Information (STI) program plays a key part in helping NASA maintain this important role.

The NASA STI Program operates under the auspices of the Agency Chief Information Officer. It collects, organizes, provides for archiving, and disseminates NASA's STI. The NASA STI program provides access to the NASA Aeronautics and Space Database and its public interface, the NASA Technical Reports Server, thus providing one of the largest collections of aeronautical and space science STI in the world. Results are published in both non-NASA channels and by NASA in the NASA STI Report Series, which includes the following report types:

- TECHNICAL PUBLICATION. Reports of completed research or a major significant phase of research that present the results of NASA programs and include extensive data or theoretical analysis. Includes compilations of significant scientific and technical data and information deemed to be of continuing reference value. NASA counterpart of peer-reviewed formal professional papers but has less stringent limitations on manuscript length and extent of graphic presentations.

- TECHNICAL MEMORANDUM. Scientific and technical findings that are preliminary or of specialized interest, e.g., quick release reports, working papers, and bibliographies that contain minimal annotation. Does not contain extensive analysis.

- CONTRACTOR REPORT. Scientific and technical findings by NASA-sponsored contractors and grantees.

- CONFERENCE PUBLICATION. Collected papers from scientific and technical conferences, symposia, seminars, or other meetings sponsored or cosponsored by NASA.

- SPECIAL PUBLICATION. Scientific, technical, or historical information from NASA programs, projects, and missions, often concerned with subjects having substantial public interest.

- TECHNICAL TRANSLATION. Englishlanguage translations of foreign scientific and technical material pertinent to NASA's mission.

Specialized services also include creating custom thesauri, building customized databases, organizing and publishing research results.

For more information about the NASA STI program, see the following:

- Access the NASA STI program home page at http://www.sti.nasa.gov

- E-mail your question via the Internet to help@ sti.nasa.gov

- Fax your question to the NASA STI Help Desk at 301-621-0134

- Telephone the NASA STI Help Desk at 301-621-0390

- Write to: NASA Center for AeroSpace Information (CASI) 7115 Standard Drive Hanover, MD 21076-1320 
NASA/TM-2008-215013

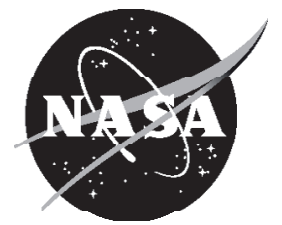

\section{NEXT Ion Thruster Performance Dispersion Analyses}

George C. Soulas and Michael J. Patterson

Glenn Research Center, Cleveland, Ohio

Prepared for the

43rd Joint Propulsion Conference

sponsored by the American Institute of Aeronautics and Astronautics

Cincinnati, Ohio, July 8-11, 2007

National Aeronautics and

Space Administration

Glenn Research Center

Cleveland, Ohio 44135 
This report contains preliminary findings, subject to revision as analysis proceeds.

Level of Review: This material has been technically reviewed by technical management.

Available from

NASA Center for Aerospace Information 7115 Standard Drive

Hanover, MD 21076-1320
National Technical Information Service 5285 Port Royal Road Springfield, VA 22161

Available electronically at http://gltrs.grc.nasa.gov 


\title{
NEXT Ion Thruster Performance Dispersion Analyses
}

\author{
George C. Soulas and Michael J. Patterson \\ National Aeronautics and Space Administration \\ Glenn Research Center \\ Cleveland, Ohio 44135
}

\begin{abstract}
The NEXT ion thruster is a low specific mass, high performance thruster with a nominal throttling range of 0.5 to $7 \mathrm{~kW}$. Numerous engineering model and one prototype model thrusters have been manufactured and tested. Of significant importance to propulsion system performance is thruster-to-thruster performance dispersions. This type of information can provide a bandwidth of expected performance variations both on a thruster and a component level. Knowledge of these dispersions can be used to more conservatively predict thruster service life capability and thruster performance for mission planning, facilitate future thruster performance comparisons, and verify power processor capabilities are compatible with the thruster design. This study compiles the test results of five engineering model thrusters and one flight-like thruster to determine unit-to-unit dispersions in thruster performance. Component level performance dispersion analyses will include discharge chamber voltages, currents, and losses; accelerator currents, electron backstreaming limits, and perveance limits; and neutralizer keeper and coupling voltages and the spot-to-plume mode transition flow rates. Thruster level performance dispersion analyses will include thrust efficiency.
\end{abstract}

\section{Introduction}

The NASA Glenn Research Center (GRC) is responsible for the development of the NEXT (NASA's Evolutionary Xenon Thruster) ion propulsion system (ref. 1). This system is a next generation ion propulsion system to follow the successful NSTAR (NASA's Solar Electric Propulsion Technology Applications Readiness program) ion propulsion system that propelled NASA's Deep Space 1 spacecraft and will be used to propel the Dawn spacecraft (Refs. 2 and 3). Propulsion system elements under development by the NEXT program include a high performance, $7 \mathrm{~kW}$ ion thruster (Ref. 4); a modular, high-efficiency $7 \mathrm{~kW}$ power processor unit (Ref. 5); a highly flexible, advanced xenon propellant management system (Ref. 6); and a compact, light-weight thruster gimbal (Ref. 7). This design approach was selected to provide future NASA science missions with the greatest value in mission performance at a low total development cost.

A key component of the propulsion system is the ion thruster. The NEXT ion thruster is a low specific mass, cylindrical thruster with a beam extraction diameter of $36 \mathrm{~cm}$. Though originally a $40 \mathrm{~cm}$ extraction diameter, analyses following an early wear test showed that service life could be improved by reducing the perforated diameter without any significant loss of thruster performance (Ref. 8). The development of the ion thruster was led by NASA GRC. Laboratory model thrusters were initially manufactured for proof of concept performance tests. The NEXT program then turned to manufacturing higher fidelity, engineering model (or EM) thrusters for performance, wear, and vibration testing, as well as supporting system-level testing such as integration tests and a recent multithruster array test (Refs. 9 to 14). This technology was transferred to NEXT's industry partner, Aerojet, who designed a flight-like prototype model (or PM) thruster (Ref. 4). To date, the NEXT program has manufactured and tested five EM thrusters and one PM thruster. All EM thrusters were manufactured by NASA GRC while the PM thruster was manufactured by Aerojet. All EM and PM thrusters have undergone some form of performance testing (Refs. 9 to 15 ).

Now that numerous NEXT thrusters have been built and tested, thruster-to-thruster dispersion analyses can be conducted. This type of information can provide a bandwidth of expected thruster performance deviations that result from minor differences from thruster to thruster. Analyses can be conducted both on a thruster and on a component level. Knowledge of thruster-to-thruster dispersions can be used to more conservatively predict thruster service life capability and thruster performance for mission planning, facilitate future thruster performance comparisons, and verify power processor capabilities are compatible with the thruster design.

This paper will compile the test results of five EM thrusters and one PM thruster to determine thruster-to-thruster dispersions in performance while operating in steady-state. Component and thruster level performance dispersions will be presented. 


\section{Scope}

It is important to distinguish between the different causes of dispersion in thruster performance and operating parameters. These are listed below:

(1) thruster-to-thruster dispersions due to differences between thrusters;

(2) test-to-test dispersions for a given thruster due to subtle changes in the thruster from one test to the next;

(3) test dispersions over a short operating time for a given thruster due to subtle changes in the thruster during that time;

(4) dispersions for a given thruster due to measurement uncertainty;

(5) dispersions for a given thruster due to external environmental effects such as pressure and temperature;

(6) dispersions during thruster startup for a given thruster due to thruster thermal and pressure effects; and

(7) dispersions over long durations for a given thruster due to thruster wear.

Most dispersion causes are interrelated. For example, thruster-to-thruster dispersions will inevitably include testto-test dispersions and dispersions over a short time. Regardless, these dispersion causes can readily be assessed. In addition, the effect of the latter three can be mitigated by operating in a vacuum facility with a high pumping speed, operating the thruster until operating parameters reach stead-state, and by only examining beginning-of-life thruster data, which can include up to $2000 \mathrm{~h}$ of accumulated operation for most operating parameters according to the results of References 8 to 10 and 13 .

The objective of this paper will be to analyze thruster-to-thruster dispersions in several performance and operating parameters. Measurement uncertainties, analyzed in Reference 16, will be included in the results. Dispersions during thruster startup, sometimes referred to as startup transients and which can be inferred from Reference 14, will not be analyzed in this paper. Therefore, only data measured during thruster operation in steadystate will be considered in this investigation. Dispersions due to background pressure will also be excluded, and its effect will be minimized by only comparing data for thruster tested in facilities with high pumping speeds as appropriate. Finally, dispersions due to thruster wear is the topic of a past wear test and ongoing long duration test reports and will, therefore, not be analyzed here (Refs. 8 to 10 and 13).

Dispersions in both component and thruster level operation and performance will be investigated. Component level operation and performance dispersion analyses will include:

(1) discharge chamber voltages, currents, and losses;

(2) accelerator currents, electron backstreaming limits, and impingement-limited total voltages (or perveance limits); and

(3) neutralizer keeper and coupling voltages and the spot-to-plume mode transition flow rates.

Thruster level performance dispersion analyses will include thrust efficiencies.

\section{Thruster Descriptions}

\section{A. EM Thruster}

An example of a NEXT EM ion thruster is shown in Figure 1. The thruster utilizes a $40 \mathrm{~cm}$ beam extraction diameter, though this was later reduced to $36 \mathrm{~cm}$ to eliminate the sputter erosion of these outer perimeter accelerator apertures (Ref. 8). The technical approach with the NEXT thruster design is a continuation of the "derating" philosophy used for the NSTAR ion thruster. Increasing the beam area allowed operation at significantly higher thruster input power while maintaining low voltages and ion current densities. Thus, potential complications associated with high voltage electrode operations are avoided, and thruster longevity can be maintained.

The NEXT EM discharge chamber design utilizes a hollow cathode electron emitter and a semi-conic chamber with a ring cusp magnetic circuit for electron containment created by high strength, rare earth magnets. A flake-retention scheme is employed in the discharge chamber, which also acts as a magnet retainer. The material, preparation, and installation processes employed for the flake-retention system are

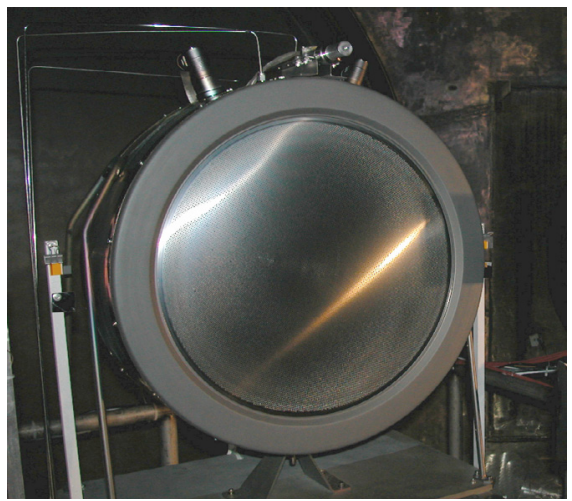

Figure 1. -NEXT EM1 ion thruster mounted in VF6 at NASA GRC for wear testing. 
identical to those implemented on the NSTAR thruster (Ref. 17). The discharge chamber also incorporates a reversefeed propellant injection process for the main plenum. Finally, the NEXT EM thruster design utilizes compact propellant isolators with a higher voltage isolation capability (about $1800 \mathrm{~V}$ ) than those used by the NSTAR thruster.

The NEXT ion thruster employs a neutralizer design that is mechanically similar to the Hollow Cathode Assembly of the International Space Station Plasma Contactor (Ref. 18). Because the neutralizer cathode emission current range on the NEXT ion thruster is similar to that of the Hollow Cathode Assembly, the NEXT neutralizer design can leverage off of the large database already available with this design for risk reduction (Ref. 19).

The ion optics mounting assembly is similar to that of the NSTAR ion thruster, except that the diameter was increased to accommodate the larger beam extraction diameter electrodes. The electrode geometry, referred to as Thick-Accelerator-Grid ion optics, is similar to that employed with the NSTAR thruster except that the accelerator electrode thickness was increased to enhance thruster service life (Ref. 20).

\section{B. PM Thruster}

The NEXT PM1 thruster is shown in Figure 2. Thruster dimensions critical to thruster performance, such as those associated with the cathodes, discharge chamber, ion optics, and high voltage propellant isolators, are nearly identical to those of the EM thruster. The PM design improved upon the EM thruster design with emphasis on surviving vibration and thermal environments and on reduced thruster mass. Manufacturability was also improved with this new design. The PM thruster design includes significant enhancements over the EM thruster design including: innovative coatings to increase emissivity for enhanced thermal margin, more uniform ion optics aperture diameters with much shallower cusps, a $36 \mathrm{~cm}$ beam extraction diameter to reduce edge aperture erosion, and graphite discharge cathode keeper to mitigate keeper erosion. A more detailed discussion of the PM thruster design can be found in Reference 4.

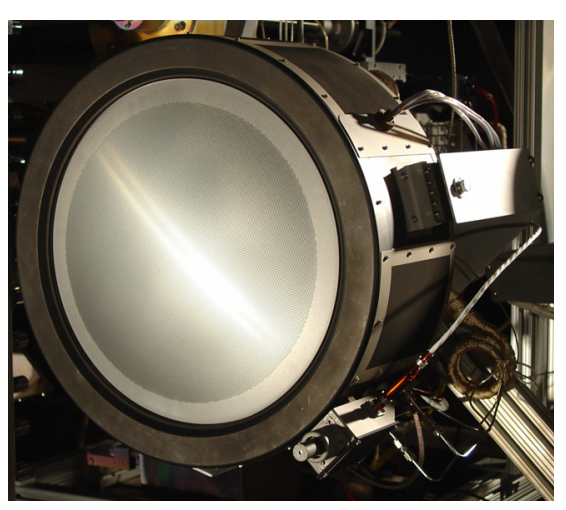

Figure 2.-NEXT PM1 mounted in VF6 at NASA GRC for performance testing.

\section{Differences Between Thrusters}

For this study, the operation and performance of five EM thrusters and one PM thruster will be analyzed. These thrusters were built at different times during the NEXT program and, as a result, have minor design differences from thruster to thruster. Table 1 below lists some of these differences.

Table 1.-Differences Between Thrusters Analyzed in This Study

\begin{tabular}{|c|c|c|c|}
\hline $\begin{array}{l}\text { Thruster } \\
\text { Designation }\end{array}$ & $\begin{array}{c}\text { Ion Optics Beam Extraction } \\
\text { Diameter }\end{array}$ & $\begin{array}{l}\text { Discharge and } \\
\text { Neutralizer } \\
\text { Cathodes }\end{array}$ & Discharge Chamber \\
\hline EM1a & $\begin{array}{c}40 \mathrm{~cm}(\mathrm{New}) \\
40 \mathrm{~cm}(\text { Pre-orated })^{\mathrm{a}}\end{array}$ & All New & $\begin{array}{c}\text { New } \\
\text { Pre-onerated }\end{array}$ \\
\hline EM1b & $40 \mathrm{~cm}$ (Pre-operated) ${ }^{\mathrm{a}}$ & All New & $\begin{array}{l}\text { Pre-operated } \\
\text { Pre-operated }\end{array}$ \\
\hline EM1c & $40 \mathrm{~cm}$ (Pre-operated) ${ }^{\mathrm{a}, \mathrm{b}}$ & All New & (2000 h Wear Test) \\
\hline EM2 & $40 \mathrm{~cm}(\mathrm{New})$ & All New & New \& Pre-operated \\
\hline EM3 & $36 \mathrm{~cm}$ Flight-like $(\mathrm{New})^{\mathrm{c}}$ & $\begin{array}{l}\text { All New, Graphite } \\
\text { Discharge Keeper }\end{array}$ & New \\
\hline EM4 & $\begin{array}{l}40 \mathrm{~cm} \text { masked to } 36 \mathrm{~cm} \\
\text { (Pre-operated) })^{\mathrm{a}, \mathrm{d}}\end{array}$ & All New & New \\
\hline EM5 & $40 \mathrm{~cm}(\mathrm{New})$ & All New & New \\
\hline PM1 & $36 \mathrm{~cm}$ Flight-like (New) & $\begin{array}{l}\text { All New, Graphite } \\
\text { Discharge Keener }\end{array}$ & New \\
\hline
\end{tabular}

${ }^{\mathrm{a}}$ Pre-operation only included performance testing.

${ }^{\mathrm{b}}$ Used the same ion optics as used on EM2.

${ }^{\mathrm{c}} \mathrm{EM} 3$ used prototype model ion optics.

${ }^{\mathrm{d}}$ Ion optics from $2000 \mathrm{~h}$ wear test of Refs. 8 and 9. 
The more significant design differences between the thrusters included the ion optics beam extraction diameter and the discharge cathode keeper material. The initial beam extraction diameter for the NEXT EM thrusters was $40 \mathrm{~cm}$. Following the $2000 \mathrm{~h}$ wear test, it was found that reducing this beam extraction diameter to $36 \mathrm{~cm}$ would eliminate erosion of the outer-radius accelerator apertures due to beamlet over-focusing, reduce maximum thruster beam divergence, and reduce the neutral loss rate without significantly increasing discharge losses (Ref. 8). As a result, later tests with EM4 utilized ion optics with a $40 \mathrm{~cm}$ beam extraction diameter masked down to $36 \mathrm{~cm}$. Furthermore, the life test thruster, EM3, and PM1 used flight-like ion optics assemblies with a $36 \mathrm{~cm}$ beam extraction diameter. All other EM thrusters were tested using ion optics that retained the original $40 \mathrm{~cm}$ beam extraction diameter.

Also as a result of the $2000 \mathrm{~h}$ wear test, the discharge cathode keeper material was changed to graphite to address possible sputter erosion concerns. This design change was implemented on PM1 and on the long duration test thruster, EM3. All other EM thrusters were tested using a keeper that retained the original material.

There are also other subtle differences between all thrusters that can affect thruster operation and performance. These differences will be discussed in later sections where their impact on dispersions is presented.

\section{Test Support Hardware and Operating Conditions}

\section{A. Power Consoles, Gas Feed Systems, and Diagnostics}

All EM thrusters reported herein were operated with power consoles similar to that described in Reference 21 . These power consoles utilized six commercially available power supplies to operate the main discharge, discharge cathode heater, neutralizer keeper discharge, and neutralizer heater, and to provide constant voltages for the accelerator grid and for beam ion acceleration. Although the NEXT peak input power is about $7 \mathrm{~kW}$ with a maximum beam power supply voltage of $1800 \mathrm{~V}$, these power consoles can provide ion thruster input powers in excess of $10 \mathrm{~kW}$ with beam power supply voltages of up to $2000 \mathrm{~V}$.

High purity gas feed systems were used to provide xenon to the discharge cathode, main plenum, and neutralizer through separate mass flow controllers. These mass flow controllers not only provided a steady flow to each thruster propellant input but also provided flow rate telemetry. For some of the data presented with EM2, a NEXT breadboard propellant management system was used to provide propellant to the thruster (Ref. 11). Flow rate was controlled using variable, electro-mechanical pressure regulators and thermal throttles (Ref. 22).

During thruster operation, voltages and currents were measured with digital multimeters and shunts. These measured parameters were used to set thruster operating conditions, as well as to determine thruster performance. The accuracies of voltage, current, and mass flow rate measurements will be discussed in later sections.

\section{B. Vacuum Facilities}

All thruster tests analyzed herein were conducted in one of four different vacuum facilities at the NASA GRC. These facilities, along with their overall dimensions, pumping speeds, maximum base pressures, and maximum pressures at full power, are listed in Table 2.

Table 2.-Vacuum Facilities Details for the Results Presented in This Study

\begin{tabular}{|c|c|c|c|c|c|}
\hline $\begin{array}{c}\text { Facility } \\
\text { Designation }\end{array}$ & $\begin{array}{c}\text { Overall } \\
\text { Dimensions } \\
\text { (Diameter } \times \\
\text { Length), } \mathrm{m}\end{array}$ & $\begin{array}{c}\text { Pumping } \\
\text { Speed, } \\
\text { L/s } \mathrm{s}^{\mathrm{a}}\end{array}$ & $\begin{array}{c}\text { Max. Base } \\
\text { Pressure, } \\
\text { Pa (Torr) }\end{array}$ & $\begin{array}{c}\text { Max. } \\
\text { Background } \\
\text { Pressure, } \\
\mathrm{Pa} \text { (Torr) }\end{array}$ & Major Test \\
\hline VF5 & $4.6 \times 19.2$ & $1,500,000$ & $\begin{array}{c}<1.3 \times 10^{-4} \\
\left(<1 \times 10^{-6}\right)\end{array}$ & $\begin{array}{c}4.7 \times 10^{-4} \\
\left(3.5 \times 10^{-6}\right)\end{array}$ & $\begin{array}{c}\text { Single String } \\
\text { Integration Test (Ref. 11) }\end{array}$ \\
\hline VF6 & $7.6 \times 22.9$ & 360,000 & $\begin{array}{c}1.2 \times 10^{-4} \\
\left(9 \times 10^{-7}\right)\end{array}$ & $\begin{array}{c}4.7 \times 10^{-4} \\
\left(3.5 \times 10^{-6}\right)\end{array}$ & $\begin{array}{c}\text { 2000 h Wear Test (Refs. 8 and 9), } \\
\text { Multi-thruster Test (Ref. 12), } \\
\text { Performance Tests (Refs. 12 and 15) }\end{array}$ \\
\hline VF16 & $2.7 \times 8.5$ & 170,000 & $\begin{array}{c}4 \times 10^{-5} \\
\left(3 \times 10^{-7}\right)\end{array}$ & $\begin{array}{c}6.5 \times 10^{-4} \\
\left(4.9 \times 10^{-6}\right)\end{array}$ & $\begin{array}{c}\text { Long Duration Test } \\
\text { (Refs. 10 and 13) }\end{array}$ \\
\hline VF11 & $2.2 \times 7.9$ & 100,000 & $\begin{array}{c}4 \times 10^{-5} \\
\left(3 \times 10^{-7}\right)\end{array}$ & $\begin{array}{c}9.6 \times 10^{-4} \\
\left(7.2 \times 10^{-6}\right)\end{array}$ & Performance Tests \\
\hline
\end{tabular}

${ }^{a}$ Pumping speed with xenon. All facilities are cryogenically pumped.

${ }^{b}$ Maximum pressures are specific to the results presented in this study.

${ }^{\mathrm{c}}$ At full input power to the thruster. 
All facilities were cryogenically pumped. Other than VF5, all cryogenic pumps were external to the main volume of the facility. For all tests other than those conducted in VF11, the ion gages measuring facility pressures were mounted next to the ion thrusters.

\section{Operating Conditions}

The NEXT ion thruster is designed for solar electric propulsion applications, so the thruster was designed to throttle over a range of input powers. During the first phase of the NEXT program, during which the $2000 \mathrm{~h}$ wear and single string integration tests were conducted, the thruster input power throttling range was 1.1 to $6.9 \mathrm{~kW}$. Part of this throttle table is shown in Table 3. The accelerator voltage was increased from -250 to $-210 \mathrm{~V}$ at the start of the 2000 wear test (Refs. 8 and 9). This was done to reduce accelerator grid sputter erosion because there was significant margin between the electron backstreaming limit and the $-250 \mathrm{~V}$ accelerator voltage.

Table 3.-Portions of the Old NEXT Throttle Table Input Parameters

\begin{tabular}{|c|c|c|c|c|c|c|}
\hline $\begin{array}{c}\text { Thruster } \\
\text { Input } \\
\text { Power, } \\
\text { kW }\end{array}$ & $\begin{array}{c}\text { Beam } \\
\text { Current, } \\
\text { A }\end{array}$ & $\begin{array}{c}\text { Beam } \\
\text { Voltage, } \\
\text { V }\end{array}$ & $\begin{array}{c}\text { Accelerator } \\
\text { Voltage, V }\end{array}$ & $\begin{array}{c}\text { Main } \\
\text { Plenum } \\
\text { Flow Rate, } \\
\text { sccm }\end{array}$ & $\begin{array}{c}\text { Discharge } \\
\text { Cathode } \\
\text { Flow Rate, } \\
\text { sccm }\end{array}$ & $\begin{array}{c}\text { Neutalizer } \\
\text { Flow Rate, } \\
\text { sccm }\end{array}$ \\
\hline 1.07 & 1.20 & 680 & -115 & 15.7 & 3.57 & 4.01 \\
2.42 & 1.20 & 1800 & -250 & 15.7 & 3.57 & 4.01 \\
2.40 & 2.00 & 1020 & -175 & 27.1 & 3.87 & 4.41 \\
2.71 & 2.00 & 1180 & -200 & 27.1 & 3.87 & 4.41 \\
3.96 & 2.00 & 1800 & -250 & 27.1 & 3.87 & 4.41 \\
3.18 & 2.70 & 1020 & -175 & 37.6 & 4.26 & 4.75 \\
5.30 & 2.70 & 1800 & -250 & 37.6 & 4.26 & 4.75 \\
4.66 & 3.52 & 1180 & -200 & 49.6 & 4.87 & 5.16 \\
$6.85^{\mathrm{e}}$ & $3.52^{\mathrm{d}}$ & $1800^{\mathrm{e}}$ & $-250 /-210^{\mathrm{d}, \mathrm{e}}$ & 49.6 & $4.87^{\mathrm{e}}$ & $5.16^{\mathrm{e}}$ \\
\hline
\end{tabular}

${ }^{\mathrm{a}}$ Predicted values.

${ }^{\mathrm{b}}$ Power supply voltage.

'Neutralizer flow with beam extraction; without beam extraction and for ignition, flow is set to $6.00 \mathrm{sccm}$.

${ }^{\mathrm{d}}$ Two thousand hour wear test operating point (Refs. 8 and 9).

${ }^{\mathrm{C}}$ Accelerator voltage increased from $-250 \mathrm{~V}$ to $-210 \mathrm{~V}$ just at the start of the $2000 \mathrm{~h}$ wear test (Refs. 8 and 9).

${ }^{\mathrm{f}}$ Neutralizer keeper current was 3.0 A throughout the throttle table.

Table 4.-Portions of the New NEXT Throttle Table Input Parameters

\begin{tabular}{|c|c|c|c|c|c|c|}
\hline $\begin{array}{l}\text { Thruster } \\
\text { Input } \\
\text { Power, }{ }^{a} \\
\text { kW }\end{array}$ & $\begin{array}{c}\text { Beam } \\
\text { Current, } \\
\text { A }\end{array}$ & $\begin{array}{c}\text { Beam } \\
\text { Voltage, }^{b} \\
\text { V }\end{array}$ & $\begin{array}{l}\text { Accelerator } \\
\text { Voltage, V }\end{array}$ & $\begin{array}{c}\text { Main } \\
\text { Plenum } \\
\text { Flow Rate, } \\
\text { sccm }\end{array}$ & $\begin{array}{c}\text { Discharge } \\
\text { Cathode } \\
\text { Flow Rate, } \\
\text { sccm }\end{array}$ & $\begin{array}{c}\text { Neutalizer } \\
\text { Flow Rate, } \\
\text { sccm }\end{array}$ \\
\hline 0.53 & 1.00 & 275 & -500 & 12.3 & 3.52 & 3.00 \\
\hline 0.66 & 1.20 & 300 & -525 & 14.2 & 3.57 & 3.00 \\
\hline 1.11 & 1.20 & 680 & -115 & 14.2 & 3.57 & 3.00 \\
\hline 2.43 & 1.20 & 1800 & -210 & 14.2 & 3.57 & 3.00 \\
\hline 2.46 & 2.00 & 1020 & -175 & 25.8 & 3.87 & 2.50 \\
\hline 2.77 & 2.00 & 1180 & -200 & 25.8 & 3.87 & 2.50 \\
\hline 4.00 & 2.00 & 1800 & -210 & 25.8 & 3.87 & 2.50 \\
\hline 3.20 & 2.70 & 1020 & -175 & 37.6 & 4.26 & 3.50 \\
\hline 5.27 & 2.70 & 1800 & -210 & 37.6 & 4.26 & 3.50 \\
\hline 4.68 & 3.52 & 1180 & -200 & 49.6 & 4.87 & 4.01 \\
\hline $6.83^{\mathrm{d}}$ & $3.52^{\mathrm{d}}$ & $1800^{\mathrm{d}}$ & $-210^{\mathrm{d}}$ & $49.6^{\mathrm{d}}$ & $4.87^{\mathrm{d}}$ & $4.01^{\mathrm{d}}$ \\
\hline
\end{tabular}


Later in the NEXT program, the throttle table was modified to both enhance thruster performance, especially at the lower power levels, and to expand the lower power throttling envelope. The result was a nominal input power throttling range of 0.5 to $6.8 \mathrm{~kW}$, which is shown in Table 4 . Changes included the addition of lower input power levels, increasing the discharge propellant utilization efficiency at the lower power levels, and decreasing the neutralizer flow rate throughout the throttle table to improve overall propellant utilization efficiency. Tests utilizing this new throttle table included the long duration and the multi-thruster tests.

Testing with each thruster presented herein was conducted using both throttle tables in various facilities and tests. To distinguish between these different tests, Table 5 lists each thruster with associated tests, facilities, and throttle tables.

Table 5.-Thruster Tests, Vacuum Facilities, and Throttle Tables Analyzed in This Study

\begin{tabular}{|c|c|c|c|}
\hline $\begin{array}{c}\text { Thruster } \\
\text { Designation }\end{array}$ & Test & $\begin{array}{c}\text { Vacuum } \\
\text { Facility }\end{array}$ & Throttle Table \\
\hline EM1a & Performance Test (Ref. 14) & VF6 & Old (Table 3) \\
EM1b & 2000 h Wear Test (Ref. 9) & VF6 & Old (Table 3) \\
EM1c & Multi-thruster Test (Ref. 12) & VF6 & New (Table 4) \\
EM2 & Single String Integration Test (Ref. 11) & VF5, VF11 & Old (Table 3) \\
EM3 & Long Duration Test (Ref. 10) & VF16 & Old and new \\
EM4 & Multi-thruster Test (Ref. 12) & VF6 & New (Table 4) \\
EM5 & Multi-thruster Test (Ref. 12) & VF6 & New (Table 4) \\
PM1 & Performance Test (Ref. 22) & VF6 & New (Table 4) \\
\hline
\end{tabular}

\section{Dispersion Analysis Results and Discussions}

The following sections will tabulate thruster-to-thruster dispersions in discharge chamber, ion optics, and neutralizer performance and operating parameters, and in thrust efficiency. Dispersion for a given parameter is defined here as the difference between the maximum and minimum deviations from an average value. These maximum and minimum deviations will also be tabulated, along with the average values. Measurement uncertainties will also be presented. To simplify analyses, performance results will typically be analyzed at the following beam currents and beam power supply voltages: $3.52 \mathrm{~A}$ and $1800 \mathrm{~V} ; 2.00 \mathrm{~A}$ and $1180 \mathrm{~V}$; and $1.20 \mathrm{~A}$ and $680 \mathrm{~V}$, respectively. These throttling points were selected because they both span most of the power throttling range and provide the largest amount of data available for analyses. Only data measured during thruster operation in steadystate were included in these analyses.

\section{A. Discharge Chamber}

Four discharge chamber performance and service life-related parameters were analyzed, and these included discharge voltage and current, discharge losses, and discharge keeper voltage. The former two parameters are important to thrust efficiency because they define the discharge losses (i.e. the power lost for beam ion generation). Discharge losses are defined as the product of the discharge current and voltage divided by the beam current. Both discharge and discharge keeper voltages are also important for determining the wear rates of discharge chamber components, such as the keeper, cathode, and ion optics' screen grid.

All voltages were measured with voltmeters to an accuracy of at least \pm 0.3 percent. For all EM thrusters, separate sense leads were attached to the cathode and anode of the discharge chamber to eliminate voltage drops. For PM1, voltages drops were estimated based on measured wire lengths and assumed temperatures, and these drops were subtracted from the voltage measurements for proper comparisons. The uncertainty in discharge voltage measurements is therefore the accuracy of the voltmeter (i.e. \pm 0.3 percent). Although there was no separate sense lead for measuring discharge keeper voltages, keeper currents are typically only about $20 \mathrm{~mA}$, so the uncertainty in the discharge keeper voltage measurements was determined to about \pm 0.4 percent due to the small voltage drops from the low current. Regardless of the voltage measurement uncertainties, the $2000 \mathrm{~h}$ wear and long duration tests have demonstrated that discharge and discharge keeper voltages can vary by as much as $0.1 \mathrm{~V}$ over short durations, so results will only be presented to a precision of $0.1 \mathrm{~V}$ (Refs. 8 and 13).

Discharge currents were measured with shunt resistors and current probes to an accuracy of \pm 1.0 percent while beam currents were measured with a multimeter to an accuracy of \pm 0.5 percent so these accuracies are the measurement uncertainties. Based on the above uncertainties, the uncertainty in discharge losses was determined to be \pm 1.2 percent 
Table 6 below lists the discharge voltage, current, loss, and keeper voltage averages, deviations, and dispersions. As the table shows, thruster-to-thruster dispersions in discharge current were approximately constant at all power levels at about $1 \mathrm{~A}$. Discharge voltage dispersions, however, increased with decreasing beam current. As a result, discharge loss dispersions were highest at the lowest beam current, increasing from $9 \mathrm{~W} / \mathrm{A}$ at full power to $17 \mathrm{~W} / \mathrm{A}$ at the $1.20 \mathrm{~A}$ beam current case. In all cases, measurement uncertainties were a small fraction of the thruster-tothruster dispersions, so this uncertainty was not the primary cause for these differences. The dispersions in the discharge voltages, currents, and losses are, therefore, due to subtle differences between the thrusters. An examination of the discharge chamber performance modeling efforts shows that there are a number of possible design differences that can affect dispersions in both discharge voltages and losses (Refs. 23 and 24). Because the discharge current is used to maintain a constant beam current, the dispersions in discharge voltages and losses lead to dispersions in discharge currents as well. These thruster differences can include, but are not necessarily limited to: grid neutral transparency differences that can affect the chamber neutral density and electron temperatures; magnetic field differences, especially at the cusps, that can affect the loss area for primary electrons; and discharge cathode differences, especially with the electron emitter, that can affect power losses and discharge voltages.

Table 6.-Discharge Voltage, Current, Loss, and Keeper Voltage Averages, Deviations, and Dispersions

\begin{tabular}{|c|c|c|c|c|}
\hline \multicolumn{2}{|c|}{ Discharge Parameter ${ }^{\mathrm{a}}$} & \multicolumn{3}{|c|}{$\begin{array}{c}\text { Operating Condition } \\
\text { (Beam Current, Beam Power Supply Voltage) }\end{array}$} \\
\hline & & $3.52 \mathrm{~A}, 1800 \mathrm{~V}$ & $2.00 \mathrm{~A}, 1180 \mathrm{~V}$ & $1.20 \mathrm{~A}, 680 \mathrm{~V}$ \\
\hline \multirow{4}{*}{ Discharge Voltage, $\mathrm{V}$} & Average & 23.8 & 24.5 & 27.3 \\
\hline & Upper Deviation & +0.5 & +0.4 & +0.5 \\
\hline & Lower Deviation & -0.4 & -1.0 & -1.2 \\
\hline & Dispersion & 0.9 & 1.4 & 1.7 \\
\hline \multirow{4}{*}{ Discharge Current, A } & Average & 19.0 & 13.4 & 9.6 \\
\hline & Upper Deviation & +0.5 & +0.4 & +0.7 \\
\hline & Lower Deviation & -0.6 & -0.4 & -0.6 \\
\hline & Dispersion & 1.1 & 0.8 & 1.3 \\
\hline \multirow{4}{*}{ Discharge Losses, W/A } & Average & 128 & 164 & 217 \\
\hline & Upper Deviation & +4 & +7 & +7 \\
\hline & Lower Deviation & -5 & -9 & -10 \\
\hline & Dispersion & 9 & 16 & 17 \\
\hline \multirow{4}{*}{$\begin{array}{c}\text { Discharge Keeper } \\
\text { Voltage, V }\end{array}$} & Average & 4.5 & 3.5 & 3.1 \\
\hline & Upper Deviation & +0.8 & +0.4 & +1.0 \\
\hline & Lower Deviation & -0.5 & -0.7 & -0.7 \\
\hline & Dispersion & 1.3 & 1.1 & 1.7 \\
\hline
\end{tabular}

${ }^{\mathrm{a}}$ All thrusters were included in these analyses other than EM5 (which exhibited anomalously low discharge losses for unknown reasons) and EM1a (because the grid gap was too small, which affected the discharge losses). In addition, because background pressure can impact discharge losses, data from tests conducted in VF11 were excluded. Finally, only new throttle table results are presented for beam currents of $2.00 \mathrm{~A}$ and $1.20 \mathrm{~A}$. Test results using the old throttle table, however, exhibited similar dispersions.

The dispersions listed in Table 6 are well within acceptable limits. The ultimate impact of thruster-to-thruster discharge loss dispersions on thruster performance will be its impact on thrust efficiency, which will later be shown to be small. Discharge voltage and keeper voltage maximum and minimum deviations, respectively, were also low enough to prevent any anomalously high wear rates. This includes the discharge voltage's impact on doubly-charged ion production, which affects wear rates. Reference 13 shows that at full power, a discharge voltage increase of $0.5 \mathrm{~V}$ will only increase the percentage of doubly- to singly-charged ions from 8 to 9 percent, which is negligibly small. Finally, discharge current and voltage dispersions were well within the NEXT power processor capabilities, even when estimated changes in discharge currents and voltages due to wear are considered (Ref. 13).

\section{Ion Optics}

Two ion optics service life parameters and one performance parameter were analyzed, and these included accelerator currents, electron backstreaming limits, and impingement-limited total voltages (or perveance limits). Thruster-to-thruster accelerator current dispersions are significant because the primary life-limiting mechanism of the NEXT thruster is sputter erosion of the accelerator grid. Thruster-to-thruster dispersions in the electron 
backstreaming limit are also important because electron backstreaming due to aperture enlargement from sputter erosion is another failure mechanism. Finally, perveance limit dispersions are important because they define the beam current extraction capability of the thruster.

Accelerator currents were measured with shunt resistors to an accuracy of \pm 1.0 percent. Electron backstreaming limits were determined by lowering the magnitude of the accelerator grid voltage until the indicated beam power supply current increased by $1 \mathrm{~mA}$ due to backstreaming electrons. Although the accuracy of the accelerator voltage measurement was \pm 0.5 percent, the measurement technique was estimated to produce results to an uncertainty of about $\pm 2.5 \mathrm{~V}$, which includes measurement uncertainty and estimated repeatability and operator error. Perveance limits were determined from plots of accelerator current as a function of total voltage where the slope was $-0.02 \mathrm{~mA} / \mathrm{V}$. Here, the total voltage is defined as the sum of the beam power supply voltage and the absolute value of the accelerator voltage. Total voltages were measured to an uncertainty of \pm 1.1 percent, which would produce an uncertainty of \pm 1.5 percent for the slope calculation when combined with the accuracy of the current measurement. However, a significant contributor to the uncertainty of the perveance limit determination was the voltage increments used to identify this limit. The voltage increments were typically $10 \mathrm{~V}$, but were also as large as $25 \mathrm{~V}$ in some cases. The larger increment dominated the uncertainty of the measurement, resulting in an uncertainty of \pm 4.9 percent at the lower perveance limits to \pm 2.8 percent at the higher perveance limits.

Table 7 below lists the ion optics accelerator current, electron backstreaming limit, and perveance limit averages, deviations, and dispersions. Thruster-to-thruster dispersions in accelerator current were about $1 \mathrm{~mA}$ at the two lower beam currents. This increased to $2 \mathrm{~mA}$ at the $3.52 \mathrm{~A}$ beam current case. In all cases, measurement uncertainties were a small fraction of the thruster-to-thruster dispersions, so measurement uncertainty was not the cause for these differences. The increasing accelerator current dispersions with increasing beam current was most likely due to pressure differences during testing. In addition, dispersions may also have been due to inadvertent data collection following a recycle. The $2000 \mathrm{~h}$ wear test revealed that accelerator currents immediately following a recycle could be up to $1 \mathrm{~mA}$ higher than nominal at full power and require up to 10 minutes for the current to return to its nominal value (Ref. 9).

Table 7.- Ion Optics Accelerator Current, Electron Backstreaming Limit, and Perveance Limit Averages, Deviations, and Dispersions

\begin{tabular}{|c|c|c|c|c|}
\hline \multirow{2}{*}{\multicolumn{2}{|c|}{ Ion Optics Parameter ${ }^{\mathrm{a}}$}} & \multicolumn{3}{|c|}{$\begin{array}{c}\text { Operating Condition } \\
\text { (Beam Current, Beam Power Supply Voltage) }\end{array}$} \\
\hline & & $3.52 \mathrm{~A}, 1800 \mathrm{~V}$ & $2.00 \mathrm{~A}, 1180 \mathrm{~V}$ & $1.20 \mathrm{~A}, 680 \mathrm{~V}$ \\
\hline \multirow{4}{*}{ Accelerator Current, ${ }^{\mathrm{b}} \mathrm{mA}$} & Average & 13.4 & 5.5 & 3.1 \\
\hline & Upper Deviation & +1.1 & +0.7 & +0.6 \\
\hline & Lower Deviation & -0.9 & -0.6 & -0.3 \\
\hline & Dispersion & 2.0 & 1.3 & 0.9 \\
\hline \multirow{4}{*}{$\begin{array}{c}\text { Electron Backstreaming } \\
\text { Limit, V }\end{array}$} & Average & -174 & -105 & -54 \\
\hline & Upper Deviation & +7 & +3 & +4 \\
\hline & Lower Deviation & -6 & -6 & -4 \\
\hline & Dispersion & 13 & 9 & 8 \\
\hline \multirow{4}{*}{$\begin{array}{l}40 \mathrm{~cm} \text { Ion Optics } \\
\text { Impingement-limited } \\
\text { Total Voltage, }{ }^{c} \mathrm{~V}\end{array}$} & Average & 1060 & 811 & 653 \\
\hline & Upper Deviation & +20 & +20 & +32 \\
\hline & Lower Deviation & -10 & -21 & -13 \\
\hline & Dispersion & 30 & 41 & 45 \\
\hline \multirow{4}{*}{$\begin{array}{l}36 \mathrm{~cm} \text { Flight-like Ion } \\
\text { Optics Impingement- } \\
\text { limited Total Voltage, } \mathrm{V}\end{array}$} & Average & 855 & 675 & 553 \\
\hline & Upper Deviation & +5 & +5 & +17 \\
\hline & Lower Deviation & -5 & -5 & -23 \\
\hline & Dispersion & 10 & 10 & 40 \\
\hline
\end{tabular}

${ }^{a}$ All thrusters were included in these analyses other than EM5 (which exhibited anomalously low electron backstreaming limits due in part to a large peak beam current density) and EM1a (because the grid gap was too small, which affected the electron backstreaming and perveance limits).

${ }^{\mathrm{b}}$ Because high background pressures can significantly increase accelerator currents, data from tests conducted in VF11 were excluded. Also, EM3 data from the second performance test (i.e. after $1050 \mathrm{~h}$ of operation) were used because all pumps were fully operational, providing the lowest background pressure. Finally, only data using the new throttle table were analyzed at the two lower beam currents.

${ }^{\mathrm{c}}$ Includes data from EM4 with the $40 \mathrm{~cm}$ ion optics set that was masked down to $36 \mathrm{~cm}$. 
Thruster-to-thruster dispersions in the electron backstreaming limits increased from 8 Vat low power to $13 \mathrm{~V}$ at full power. Unlike the accelerator current, the measurement uncertainty was a large fraction of the dispersions, and therefore accounted for at least some of these dispersions. Other minor thruster-to-thruster differences in the grid geometry, such as the accelerator aperture diameter or the grid gap, or differences in the peak beamlet currents, were probable causes of the remaining dispersions in these measured limits.

Beam extraction diameter had no noticeable impact on the accelerator currents or the electron backstreaming limit, which was not surprising. Because the outer $2 \mathrm{~cm}$ of beam radius were found to contribute little to the overall beam current, accelerator currents should be similar for both beam extraction diameters. Furthermore, electron backstreaming is a local phenomenon that is dominated by a region of the optics that has the smallest gap, the largest accelerator aperture diameters, and the highest beamlet currents, all of which are typically found at the center of the NEXT ion optics. The center aperture diameters and grid gaps measured at room temperature were similar for all thrusters analyzed in this study.

The impingement-limited total voltage is an integrated effect, though. While beam extraction diameter was not expected to impact perveance, the $36 \mathrm{~cm}$ flight-like ion optics used on EM3 and PM1 had more constant accelerator aperture diameters throughout the beam extraction area than the masked or unmasked $40 \mathrm{~cm}$ ion optics. The $40 \mathrm{~cm}$ optics had accelerator aperture diameters that decreased significantly from the grid center to edge (Ref. 8). As a result, the $36 \mathrm{~cm}$ flight-like ion optics exhibited perveance limits that were 100 to $200 \mathrm{~V}$ lower than the $40 \mathrm{~cm}$ ion optics, as shown in Table 7.

As a result, perveance limit dispersions for the $40 \mathrm{~cm}$ ion optics (both masked and unmasked) and the $36 \mathrm{~cm}$ flight-like ion optics were examined separately. Thruster-to-thruster dispersions at the lowest beam current were similar for both optics designs, but were lower at the higher beam current for the flight-like design. This is likely because only two flight-like ion optics were analyzed in this study. Even at the largest dispersions, though, the measurement uncertainty was a large fraction of the dispersions, and therefore accounted for at least some of the dispersion. Other minor thruster-to-thruster differences in the grid geometry, such as the accelerator aperture diameter or the grid gap, caused the remaining dispersions in these measured limits.

The thruster-to-thruster dispersions in electron backstreaming and perveance limits of Table 7 were not large, with measurement uncertainties accounting a large fraction of these dispersions. The improved perveance of the flight-like $36 \mathrm{~cm}$ ion optics can also be exploited to improve service life capability of the accelerator grid at lower power levels of the new NEXT throttle table, where large accelerator voltage magnitudes are required to extract the desired beam current. Although accelerator current dispersions were a large fraction of the nominal values, dispersions were likely due to differences in background pressure.

\section{Neutralizer}

Three neutralizer performance parameters were analyzed, and these included the neutralizer keeper voltage, the coupling voltage (i.e. neutralizer common potential relative to facility ground), and the spot-plume mode transition flow rate. Thruster-to-thruster dispersions in neutralizer keeper and coupling voltages are important because of their impact on thruster performance, especially at lower thruster input powers. Dispersions in the transition flow rates between spot and plume modes are important to the service life capability of the neutralizer cathode, as well as thruster performance.

Both voltages were measured with voltmeters to an accuracy of at least $\pm 0.3 \%$. No sense leads were attached to the neutralizer, however, so the resulting voltages included voltage drops. Unfortunately, these voltage drops varied because of the different wire lengths used for each test. Calculations show that neutralizer keeper and coupling voltage drops could have ranged from 0.5 to $1.1 \mathrm{~V}$ and 0.3 to $0.7 \mathrm{~V}$, respectively, depending on wire length and beam current.

Mass flow rates were typically measured with mass flow controllers to an accuracy of \pm 1.0 percent, though flow rates for EM2 tests with the NEXT breadboard propellant management system had an accuracy of \pm 3.0 percent. A large contributor to the uncertainty of the transition flow rate was the flow rate increments used to identify this limit. The flow rate increments were as large as $0.25 \mathrm{sccm}$ in some cases. This large increment contributed significantly the uncertainty of the transition flow rate, resulting in an uncertainty of \pm 7.2 percent at the lower transition flow rates to \pm 5.1 percent at the higher transition flow rates.

Table 8 below lists the neutralizer keeper and coupling voltage averages, deviations, and dispersions for operation with each throttle table separately. Thruster-to-thruster dispersions in keeper voltages were 1 to $2.4 \mathrm{~V}$ with the higher neutralizer flow rates of the old throttle table (i.e. Table 3). These dispersions increased to up to $6.2 \mathrm{~V}$ with the lower flow rates of the new throttle table (i.e. Table 4). These increased dispersions were expected because performance testing with the Hollow Cathode Assemblies showed that operating close to the transition flow rate can 
increase unit-to-unit keeper voltage dispersions. The keeper voltage measurement uncertainty was a large fraction of the dispersions for the results with the old throttle table. However, this was not the case for results with the new throttle table at the lower beam currents. So, while measurement uncertainties may have accounted for at least some of the dispersion with the old throttle table, other effects caused the larger dispersions with the new throttled flow rates at the lower beam currents. These effects likely included minor differences in the neutralizer cathode-keeper geometry and the electron emitters.

Thruster-to-thruster dispersions in coupling voltages were less than $0.9 \mathrm{~V}$ with the old throttle table, but these dispersions increased to 1.6 to $1.9 \mathrm{~V}$ with the lower flow rates of the new throttle table. The coupling voltage measurement uncertainty was a large fraction of the dispersions, so measurement uncertainties accounted for at least some of the dispersion. Other causes for these dispersions were also minor differences in the neutralizer cathodekeeper geometry and the electron emitters.

The neutralizer keeper and coupling voltage dispersions listed in Table 8 are within acceptable limits. The ultimate impact of these dispersions would be their impact on thrust efficiency, which will later be shown to be small. These voltage dispersions were also well within the NEXT power processor capabilities, even when estimated changes due to wear are considered (Ref. 13).

Table 8.- Neutralizer Keeper and Coupling Voltage Averages, Deviations, and Dispersions

\begin{tabular}{|c|c|c|c|c|}
\hline \multirow{2}{*}{ Neutralizer Parameter } & \multicolumn{3}{|c|}{ Operating Condition } \\
\cline { 3 - 5 } & & \multicolumn{3}{|c|}{ (Beam Current, Beam Power Supply Voltage) } \\
\cline { 3 - 5 } & Average & 11.7 & 15.3 & $1.20 \mathrm{~A}, 680 \mathrm{~V}$ \\
\hline \multirow{3}{*}{ Keeper Voltage With } & Upper Deviation & +0.9 & +2.3 & +2.7 \\
New Throttle Table, V & Lower Deviation & -0.6 & -2.7 & -3.5 \\
& Dispersion & 1.5 & 5.0 & 6.2 \\
\hline & Average & 11.1 & 11.6 & 12.9 \\
Keeper Voltage With & Upper Deviation & +0.6 & +0.5 & +1.1 \\
Old Throttle Table, V & Lower Deviation & -0.5 & -0.5 & -1.3 \\
& Dispersion & 1.1 & 1.0 & 2.4 \\
\hline & Average & -10.8 & -10.1 & -9.2 \\
Coupling Voltage With & Upper Deviation & +0.5 & +0.7 & +0.6 \\
New Throttle Table, V & Lower Deviation & -0.5 & -0.9 & -1.3 \\
& Dispersion & 1.0 & 1.6 & 1.9 \\
\hline \multirow{3}{*}{ Coupling Voltage With } & Average & -10.3 & -9.9 & -9.4 \\
Old Throttle Table, V & Upper Deviation & +0.4 & +0.3 & +0.5 \\
& Lower Deviation & -0.5 & -0.3 & -0.3 \\
& Dispersion & 0.9 & 0.6 & 0.8 \\
\hline
\end{tabular}

${ }^{a}$ All thrusters and tests were included in these analyses.

Dispersions in the transition flow rates between spot and plume modes affect both thruster service life and thrust efficiency. Because operation in plume mode can lead to excessively high cathode erosion rates, maintaining spot mode operation by operating above the transition flow rate is considered critical to maintaining thruster service life. It is, however, important to maintain a low neutralizer flow rate to achieve high thrust efficiencies, especially at the lower power levels. Selecting throttle table flow rates, therefore, requires balancing these competing effects. Consideration must also be given, though, to other effects such as thruster-to-thruster dispersions in the transition flow rates.

Table 9 below lists the neutralizer transition flow rate averages, deviations, and dispersions. Thruster-to-thruster dispersions transition flow rates ranged between 0.50 to $0.64 \mathrm{sccm}$. The transition flow measurement uncertainty was a small fraction of the dispersion results (i.e. $1 / 3$ to $1 / 5$ times the thruster-to-thruster dispersion), so measurement uncertainties only accounted for some of the dispersions. The rest of the thruster-to-thruster dispersions were likely due to minor differences in the neutralizer cathode-keeper geometry and the electron emitters.

As Table 9 shows, there is greater than $1 \mathrm{sccm}$ of flow margin between the new throttle table set point and the transition flow rate at full power. This is not the case, however, with the two lower beam currents. At worst case transition flow rate deviations, there is almost no flow margin at 2.00 and $1.20 \mathrm{~A}$ beam currents. This issue was identified earlier in the NEXT program, so the PM1 neutralizer geometry was modified to lower the spot-to-plume 
mode transition flow rates at these lower beam currents. PM1 test results showed that this design improvement was successful, increasing the flow margin to a minimum of $0.6 \mathrm{sccm}$ (including measurement uncertainty) at the lower beam currents. If worst case EM thruster neutralizer deviations are included in the PM1 results, this flow margin only decreases to a minimum of $0.4 \mathrm{sccm}$.

Table 9.-Neutralizer Spot to Plume Mode Transition Flow Rate Averages, Deviations, and Dispersions

\begin{tabular}{|c|c|c|c|c|}
\hline \multirow{2}{*}{} & \multicolumn{3}{|c|}{ Operating Condition } \\
Neutralizer Parameter & \multicolumn{3}{c|}{ (Beam Current, Beam Power Supply Voltage) } \\
\cline { 3 - 5 } \multicolumn{2}{|c|}{} & $3.52 \mathrm{~A}, 1800 \mathrm{~V}$ & $2.00 \mathrm{~A}, 1180 \mathrm{~V}$ & $1.20 \mathrm{~A}, 680 \mathrm{~V}$ \\
\hline \multirow{3}{*}{ Transition Flow Rate, } & Average & 2.19 & 2.25 & 2.69 \\
sccm & Upper Deviation & +0.31 & +0.20 & +0.26 \\
& Lower Deviation & -0.33 & -0.30 & -0.31 \\
& Dispersion & 0.64 & 0.50 & 0.57 \\
\hline
\end{tabular}

${ }^{a}$ All thrusters were included in these analyses other than PM1 (whose geometry was changed to reduce the transition flow rates at low beam currents) and EM1a (because no data were available). Data for EM2 and EM3 at beam currents of 2.00 and $1.20 \mathrm{~A}$ were measured with an $1800 \mathrm{~V}$ beam power supply voltage. EM3 data from the second performance test (i.e. after $1050 \mathrm{~h}$ of operation) were used.

\section{E. Overall Thruster Performance}

Thrust efficiency was the only thruster performance parameter analyzed in this study. Analyzing other thruster performance parameters, such as thrust or specific impulse, was not warranted because significant thrust parameters, such as thrust losses due to beam divergence or double-to-single ion content, or thrust either have not been measured or the database for these measurements is too small to be statistically meaningful. Thrust efficiency can, however, be assessed because an important input to this efficiency is the total thruster input power.

Thrust efficiency measurement uncertainty was determined to be \pm 2.1 percent and only included uncertainties associated with the measured currents, voltages, and mass flow rates. Table 10 below lists the thrust efficiency averages, deviations, and dispersions. Thruster-to-thruster thrust efficiency dispersions increased with decreasing beam current to a maximum of 2.3 percent. The increased dispersions at the lower beam current were due to the increased dispersions in discharge losses at these lower beam currents. Discharge losses account for an increasing fraction of the total power losses as thruster input power levels decrease. It is important to consider, however, that the uncertainty in the efficiency calculation was larger than the dispersion, indicating that much, if not all of the dispersion, can be accounted for by measurement uncertainties.

Table 10.-Thrust Efficiency Averages, Deviations, and Dispersions

\begin{tabular}{|c|c|c|c|c|}
\hline \multirow{2}{*}{} & \multicolumn{3}{c|}{ Operating Condition } \\
\cline { 3 - 5 } Parameter $^{\mathrm{a}}$ & \multicolumn{2}{c|}{ (Beam Current, Beam Power Supply Voltage) } \\
\cline { 3 - 5 } & & $3.52 \mathrm{~A}, 1800 \mathrm{~V}$ & $2.00 \mathrm{~A}, 1180 \mathrm{~V}$ & $1.20 \mathrm{~A}, 680 \mathrm{~V}$ \\
\hline \multirow{3}{*}{ Thrust Efficiency } & Average & 0.709 & 0.677 & 0.527 \\
& Upper Deviation & +0.001 & +0.005 & +0.008 \\
& Lower Deviation & -0.001 & -0.002 & -0.004 \\
& Dispersion & 0.002 & 0.007 & 0.012 \\
\hline
\end{tabular}

${ }^{a}$ Only thrusters EM1c, EM3, EM4, and PM1 operating with the new throttle table were analyzed. EM3 data from the second performance test (i.e. after $1050 \mathrm{~h}$ of operation) were used.

\section{Conclusions}

The test results of five EM thrusters and one PM thruster were analyzed to determine thruster-to-thruster performance dispersions while operating in steady-state. This type of information can provide a bandwidth of expected thruster performance deviations that result from minor differences from thruster to thruster. Knowledge of these dispersions can be used to more conservatively predict thruster service life capability and thruster performance for mission planning, facilitate future thruster performance comparisons, and verify power processor capabilities are compatible with the thruster design. Component and thruster level operation and performance were analyzed. Component level performance dispersion analyses included discharge chamber voltages, currents, and losses; accelerator currents, electron backstreaming limits, and perveance limits; and neutralizer keeper and coupling voltages and spot-to-plume mode transition flow rates. Thruster level dispersion analyses included thrust efficiency. 
Discharge voltage dispersions increased with decreasing beam current, resulting in discharge loss dispersions that increased from $9 \mathrm{~W} / \mathrm{A}$ at full power to $17 \mathrm{~W} / \mathrm{A}$ at the lowest beam current case. The dispersions in the discharge voltages, currents, and losses are likely due to subtle differences between the thrusters. Regardless, these dispersions were well within acceptable limits. The impact of thruster-to-thruster discharge loss dispersions on thrust efficiency was found to be minor, at worst. Worse case voltages were also low enough to prevent any anomalously high wear rates, even when doubly-charged ion production was considered. Finally, discharge current and voltage dispersions were well within the NEXT power processor capabilities, even when changes in discharge currents and voltages due to wear are considered.

Thruster-to-thruster dispersions in accelerator current increased with increasing beam current to $2 \mathrm{~mA}$ at the $3.52 \mathrm{~A}$ beam current case. This was likely due to pressure differences during each test or data collection following a recycle. Thruster-to-thruster dispersions in the electron backstreaming limits increased from $8 \mathrm{~V}$ at low power to $13 \mathrm{~V}$ at full power while perveance limit dispersions were within $45 \mathrm{~V}$. The measurement uncertainty was a large fraction of both dispersions, and therefore accounted for at least some of the dispersions. Other minor thruster-tothruster differences in the grid geometry, such as the accelerator aperture diameter or the grid gap, or differences in the peak beamlet currents, caused the remaining dispersions in these measured limits. The $36 \mathrm{~cm}$ flight-like ion optics exhibited perveance limits that were 100 to $200 \mathrm{~V}$ lower than the $40 \mathrm{~cm}$ ion optics. This improved perveance can be exploited to improve service life capability of the accelerator grid at lower power levels.

Thruster-to-thruster dispersions in keeper voltages were 1-2.4 V with the higher neutralizer flow rates of the old throttle table, but this increased to a maximum of $6.2 \mathrm{~V}$ with the lower flow rates of the new throttle table. These increased dispersions were expected because performance testing with the Hollow Cathode Assemblies showed that operation close to the transition flow rate can increase unit-to-unit keeper voltage dispersions. Thruster-to-thruster dispersions in coupling voltages were within $1.8 \mathrm{~V}$. Both voltage dispersions were likely due to minor differences in the neutralizer cathode-keeper geometry and the electron emitters. Regardless, both voltage dispersions are well within acceptable limits. The ultimate impact of these voltage dispersions on thrust efficiency was found to be small. These voltage dispersions were also well within the NEXT power processor capabilities, even when estimated changes due to wear are considered.

Thruster-to-thruster dispersions in neutralizer spot-to-plume mode transition flow rates ranged between 0.50 to $0.64 \mathrm{sccm}$. While measurement uncertainties accounted for some of the dispersions, other causes included minor differences in the neutralizer cathode-keeper geometry and the electron emitters. At worst case transition flow rate deviations, there was nearly no flow margin at 2.00 and $1.20 \mathrm{~A}$ beam currents. This issue was identified earlier in the NEXT program, so the PM1 neutralizer geometry was modified to lower the spot-to-plume mode transition flow rates at these lower beam currents. PM1 test results showed that this design improvement was successful, increasing the flow margin to a minimum of $0.6 \mathrm{sccm}$ (including measurement uncertainty).

Thruster-to-thruster thrust efficiency dispersions increased with decreasing beam current to a maximum of 2.3 percent. The increased dispersions at the lower beam current were due to the increased dispersions in discharge losses at these lower beam currents. Discharge losses account for an increasing fraction of the total power losses as thruster input power levels decrease. However, the uncertainty in the efficiency calculation was larger than the dispersion, indicating that much, if not all of the dispersion, can be accounted for by measurement uncertainties.

\section{References}

1. Patterson, M.J. and Benson, S.W., "NEXT Ion Propulsion System Development Status and Performance," AIAA Paper 2007-5199, July 2007.

2. Polk, J.E., et al., "Demonstration of the NSTAR Ion Propulsion System on the Deep Space One Mission," IEPC Paper 01-075, October 2001.

3. Brophy, J.R., et al., "Development and Testing of the Dawn Ion Propulsion System," AIAA-2006-4319, July 2006.

4. Hoskins, W.A., et al., "Development of a Prototype Model Ion Thruster for the NEXT System," AIAA Paper 2004-4111, July 2004.

5. Todd, P.C., et al., "Status of the NEXT 7 kW Power Processing Unit," AIAA Paper 2005-3868, July 2005.

6. Aadland, R.S., et al., "Development Results of the NEXT Propellant Management System," JANNAF Conference, December 2005.

7. Vaughan, D.A., "Gimbal Development for the NEXT Ion Propulsion System," AIAA Paper 2005-3865, July 2005.

8. Soulas, G.C., et al., "NEXT Ion Engine 2000 Hour Wear Test Results," AIAA Paper 2004-3791, July 2004.

9. Soulas, G.C., et al., "Status of the NEXT Ion Engine Wear Test," AIAA Paper 2003-4863, July 2003. 
10. Frandina, M.M., et al., "Status of the NEXT Ion Thruster Long Duration Test," AIAA Paper 2005-4065, July 2005.

11. Patterson, M.J., et al., "NEXT Ion propulsion System: Single String Integration Test Results," JANNAF Conference, May 2004.

12. Patterson, M.J., et al., "NEXT Multi-thruster Array Test-Engineering Demonstration," AIAA Paper 20065180, July 2006.

13. Herman, D.A.., Soulas, G.C., and Patterson, M.J., "Status of the NEXT Ion Thruster Long Duration Test," AIAA-2007-5272, July 2007.

14. Soulas, G.C., Domonkos, M.T., and Patterson, M.J., "Performance Evaluation of the NEXT Ion Engine," AIAA Paper 2003-5278, July 2003.

15. Herman, D.A.., Soulas, G.C., and Patterson, M.J., "Performance Evaluation of the 40-cm NEXT Prototype Model Ion Thruster," AIAA 2007-5212, July 2007.

16. Stueber, T.J. and Soulas, G.C., "Electrostatic Ion Thruster Diagnostic Uncertainty Analysis," NASA/TP_-2007214665 (to be published).

17. Christensen, J.A., et al., "Design and Fabrication of a Flight Model $2.3 \mathrm{~kW}$ Ion Thruster for the Deep Space 1 Mission," AIAA Paper 98-3327, July 1998.

18. Patterson, M.J., et al., "Space Station Cathode Design, Performance, and Operating Specifications," IEPC Paper 97-170, August 1997.

19. Kovaleski, S.K., et al., "A Review of Testing of Hollow Cathodes for the International Space Station Plasma Contactor," IEPC Paper 01-271, October 2001.

20. Soulas, G.C., Patterson, M.J., and Haag, T.W., "Performance Evaluation of $40 \mathrm{~cm}$ Ion Optics for the NEXT Ion Engine," AIAA Paper 2002-3834, July 2002.

21. Pinero, L.R., Patterson, M.J., and Satterwhite, V.E., "Power Console Development for NASA's Electric Propulsion Outreach Program,” IEPC Paper 93-250, September 1993.

22. Aadland, R.S., et al., "Development Status of the NEXT Propellant Management System," AIAA Paper 20043974, July 2004.

23. Brophy, J.R. and Wilbur, P.J., "Simple Performance Model for Ring and Line Cusp Ion Thrusters," IEPC Paper 84-68, May 1984.

24. Goebel, D.M., Wirz, R.E., and Katz, I., "Analytical Ion Thruster Discharge Performance Model," AIAA Paper 2006-4486, July 2006. 


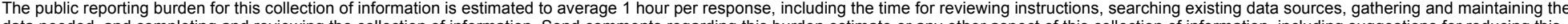

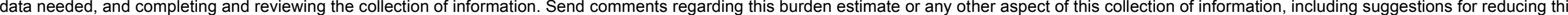

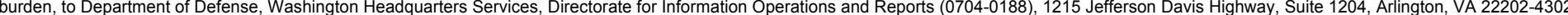

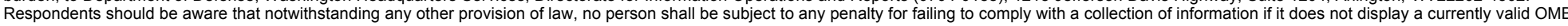
control number.

PLEASE DO NOT RETURN YOUR FORM TO THE ABOVE ADDRESS

\section{REPORT DATE (DD-MM-YYYY) \\ 2. REPORT TYPE \\ 3. DATES COVERED (From - To)}

01-01-2008

Technical Memorandum

\section{TITLE AND SUBTITLE}

NEXT Ion Thruster Performance Dispersion Analyses

\section{5a. CONTRACT NUMBER}

5b. GRANT NUMBER

5c. PROGRAM ELEMENT NUMBER

\section{AUTHOR(S)}

Soulas, George, C.; Patterson, Michael, J.

\section{5d. PROJECT NUMBER}

5e. TASK NUMBER

5f. WORK UNIT NUMBER

WBS 346620.04.05.03.11

8. PERFORMING ORGANIZATION REPORT NUMBER

E-16185

National Aeronautics and Space Administration

John H. Glenn Research Center at Lewis Field

Cleveland, Ohio 44135-3191

\section{SPONSORING/MONITORING AGENCY NAME(S) AND ADDRESS(ES)}

National Aeronautics and Space Administration

Washington, DC 20546-0001

\section{SPONSORING/MONITORS ACRONYM(S) \\ NASA \\ 11. SPONSORING/MONITORING REPORT NUMBER \\ NASA/TM-2008-215013}

\section{DISTRIBUTION/AVAILABILITY STATEMENT}

Unclassified-Unlimited

Subject Category: 20

Available electronically at http://gltrs.grc.nasa.gov

This publication is available from the NASA Center for AeroSpace Information, 301-621-0390

\section{SUPPLEMENTARY NOTES}

\section{ABSTRACT}

The NEXT ion thruster is a low specific mass, high performance thruster with a nominal throttling range of 0.5 to $7 \mathrm{~kW}$. Numerous engineering model and one prototype model thrusters have been manufactured and tested. Of significant importance to propulsion system performance is thruster-to-thruster performance dispersions. This type of information can provide a bandwidth of expected performance variations both on a thruster and a component level. Knowledge of these dispersions can be used to more conservatively predict thruster service life capability and thruster performance for mission planning, facilitate future thruster performance comparisons, and verify power processor capabilities are compatible with the thruster design. This study compiles the test results of five engineering model thrusters and one flight-like thruster to determine unit-to-unit dispersions in thruster performance. Component level performance dispersion analyses will include discharge chamber voltages, currents, and losses; accelerator currents, electron backstreaming limits, and perveance limits; and neutralizer keeper and coupling voltages and the spot-to-plume mode transition flow rates. Thruster level performance dispersion analyses will include thrust efficiency.

\section{SUBJECT TERMS}

Ion thruster; Ion engine; Ion propulsion

\section{SECURITY CLASSIFICATION OF:}

a. REPORT

$\mathrm{U}$

\section{b. ABSTRACT} U

17. LIMITATION OF
ABSTRACT
UU

\section{NUMBER \\ OF}

PAGES

19 19a. NAME OF RESPONSIBLE PERSON

STI Help Desk (email:help@sti.nasa.gov)

19b. TELEPHONE NUMBER (include area code) 301-621-0390 

